\title{
CFD ANALYSIS OF F-16 FALCON
}

\section{BABITHA KODAVANLA ${ }^{1}$, SAI KIRAN BURRA ${ }^{2}$, G. SANTOSH ${ }^{3}$,} SAI PRIYANKA ${ }^{4}$, P. ANUDEEP $^{5} \&$ V. MADHAVI ${ }^{6}$

${ }^{1,6,5}$ Assistant Professor, Department of Aeronautical Engineering, Institute of Aeronautical

Engineering, Dundigal, Hyderabad, India

${ }^{2,3}$ Graduates, Department of Aeronautical Engineering, Institute of Aeronautical

Engineering, Dundigal, Hyderabad, India

${ }^{4}$ Professor, Department of Aeronautical Engineering, Institute of

Aeronautical Engineering, Dundigal, Hyderabad, India

${ }^{6}$ Assistant Professor, Department of Aeronautical Engineering, Marri Laxman

Reddy Institute of Technology, Dundigal, Hyderabad, India

\begin{abstract}
Development of a fast-moving aircraft with high lift coefficient and low drag coefficient is an essential requirement for the current scenario to support to modernize the military capability of any independent Nation. In this context, the aim of our project is to examine the Viscous, Compressible and Steady-state flow over the F-16 Fighting Falcon aircraft using computer modeling techniques and to compare the modeled results with the analytical results to emphasize the modernization and warble capability. This project outlines the development of a computational model of the F-16 Fighting Falcon model in a finite computational domain, segmentation of this domain into discrete intervals, application of the boundary condition such as Mach number or velocity and then obtaining the plots and results for the coefficient of pressure, lift coefficient, drag coefficient, etc.

KEYWORDS: Aircraft, Lift Coefficient, CFD \& CAD
\end{abstract}

Received: Feb 26, 2018; Accepted: Mar 19, 2018; Published: Apr 04, 2018; Paper Id.: IJMPERDAPR2018149

\section{INTRODUCTION}

The aerodynamic efficiency, which plays a major role in the design and performance of fast-moving aircraft gets support with Computational Fluid Dynamics. A CFD which changed the era in the optimization of problems in the aeronautical domain. The research carried out for the need of improved computational results in the development of more accurate results from the numerical scheme of approaches, advanced solver technology, error estimations, both numerical errors and physical model errors and in the design optimizations. CFD which plays an important role principal replacement of windtunnels in of design conditions in an accurate design, modeling of turbulent approach to complex problems [1]. To improve the military capabilities of a nation fast moving aircraft with high aerodynamic efficiencies is required. F-16 fighter falcon is the one the aircraft which has high capabilities in its performance. The F-16 is combat and multi- role fighter aircraft. The design configuration of the F-16 falcon is given in detail [2]. The main role of F-16 is it's highly manoeuverable and has proven itself in an airto-air combat and air to surface attack. It provides relatively low cost and high -performance weapon system for the United States [3]. The main objective here is to find the aerodynamic efficiency and to study flow analysis around the F-16 aircraft surface [4]. The flow is subjected to different Mach Conditions at subsonic, transonic and 
supersonic Conditions subjecting to turbulent conditions and studying the flow effects at a different angle of attack[5]. In the simulation process, the model is subjected to both structured and unstructured grid Conditions which is studied in detailed. The effect of different types of grid conditions is studied in detail [6-8]. The flow properties of the surface, Shockwaves formed on the leading edge surface both at upper and lower surfaces with a change in Mach at different angles can be seen. The results are validated with the peer data available [9]. The results obtained for $C_{l}, C_{d}, C m$ and the moments on the Lockheed F-16 Falcon are accurate at the desired cases considered for different Mach (M) and Angle of attacks $(\alpha)$. The vortex flow interaction studies which change the pressure distribution on the surface are studied [10]. The present objective is to study the flow dynamics over F-16 fighter aircraft at different Mach Numbers (0.6 and 1.2). A CFD code has been based to investigate the performance parameters over the aircraft and the results have been obtained in terms of performance parameters. All the results are shown in forms of figure and contours and analyzed with a suitable concluding remark

\section{METHODS}

\section{Design Specifications}

Table 1

\begin{tabular}{|l|l|}
\hline Crew: & 1 \\
\hline Length & $49 \mathrm{ft} .5 \mathrm{in}(15.06 \mathrm{~m})$ \\
\hline Wingspan & $32 \mathrm{ft} .8 \mathrm{in}(9.96 \mathrm{~m})$ \\
\hline Height & $16 \mathrm{ft} .(4.88 \mathrm{~m})$ \\
\hline Wing area & $300 \mathrm{ft}^{2}\left(27.87 \mathrm{~m}^{2}\right)$ \\
\hline Airfoil: & NACA $64 \mathrm{~A} 204 \mathrm{root}$ and tip \\
\hline Empty weight & $18,900 \mathrm{lb}(8,570 \mathrm{~kg})$ \\
\hline Loaded weight: & $26,500 \mathrm{lb}(12,000 \mathrm{~kg})$ \\
\hline Max. take-off weight & $42,300 \mathrm{lb}(19,200 \mathrm{~kg})$ \\
\hline Internal fuel & 7,000 pounds $(3,200 \mathrm{~kg})$ \\
\hline & $\begin{array}{l}1 \times \text { General Electric F110-GE-129 (for F-16C/D Block 30- } \\
40-50) \text { or Pratt \& Whitney F100-PW-220/220E afterburning } \\
\text { Power plant }\end{array}$ \\
\hline turbo fan. \\
\hline Thry thrust & $17,155 \mathrm{lbf}(76.3 \mathrm{kN})$ \\
\hline
\end{tabular}

\section{PERFORMANCE}

Table 2

\begin{tabular}{|l|l|}
\hline Maximum speed: At sea level: & Mach $1.2(915 \mathrm{mph}, 1,470 \mathrm{~km} / \mathrm{h})$ \\
\hline At altitude & $\begin{array}{l}: \text { Mach } 2(1,320 \mathrm{mph}, 2,120 \mathrm{~km} / \mathrm{h}) \text { clean } \\
\text { configuration }\end{array}$ \\
\hline Combat radius: & $\begin{array}{l}340 \mathrm{mi}(295 \mathrm{nmi}, 550 \mathrm{~km}) \text { on a hi-lo-hi mission with } \\
\text { four } 1,000 \mathrm{lb}(450 \mathrm{~kg}) \text { bombs }\end{array}$ \\
\hline Ferry range: & $2,280 \mathrm{nmi}(2,620 \mathrm{mi}, 4,220 \mathrm{~km})$ with drop tanks \\
\hline Service ceiling: & $50,000+\mathrm{ft}(15,240+\mathrm{m})$ \\
\hline Rate of climb: & $50,000 \mathrm{ft} / \mathrm{min}(254 \mathrm{~m} / \mathrm{s})$ \\
\hline Wing loading: & $88.3 \mathrm{lb} / \mathrm{ft}^{2}\left(431 \mathrm{~kg} / \mathrm{m}^{2}\right)$ \\
\hline Thrust/weight: & $1.095(1.24 \mathrm{with} l o a d e d ~ w e i g h t ~ \& ~ 50 \%$ internal fuel $)$ \\
\hline Maximum g-load: & $+9.0 \mathrm{~g}$ \\
\hline
\end{tabular}




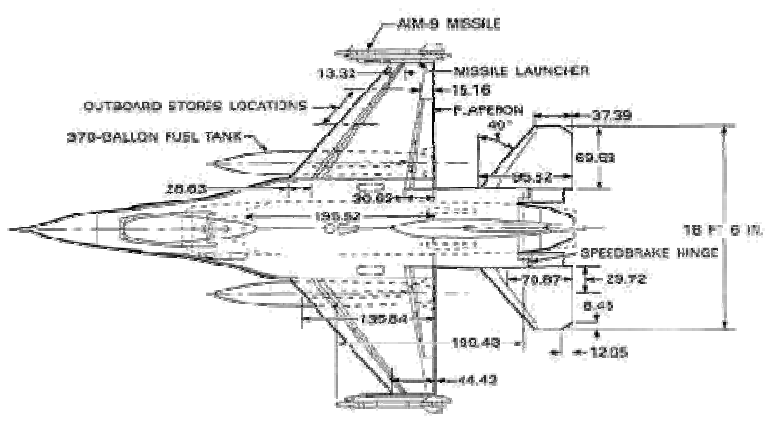

Figure 1: Top View of F-16 with Dimensions Ref (11)

\section{METHODOLOGY}

The Design and Analysis of Wing are Composed of two different approaches in computational domains: Geometry Selection and generation of geometry and importing the geometry and evaluation.

In design, the basic configuration arrangement, size, shape, and lengths are calculated. Thus, designing the CAD model of the required parts. The modeling of the F-16 Aircraft, which is used in this paper, is done using CATIA V5R20. It is a solid model over which the external flow analysis is done. Some of the sketches commands used; in this particular aircraft modeling are the line, circle, ellipse, spline, etc. And the feature commands used are loft boss, sweep boss; extrude cut, mirror, etc. While modeling this aircraft, intensive care must be taken as any improper way of modeling this may lead to overlapping of the geometry. Hence it should be seen that not two geometrical entities intersect each other. This kind of care is necessary at this stage it because later when mashing is done, it gives an enormous number of errors and would result in the poor quality mesh.

In Analysis, the generated CAD model is imported; during preprocessing the geometry (physical bounds) of the problem is defined. The volume occupied by the fluid is divided into discrete cells (the mesh). The mesh may be uniform or non-uniform. The physical modeling is defined - for example, the equations of motion + enthalpy + radiation + species conservation. Boundary conditions are defined. This involves specifying the fluid behavior and properties at the boundaries of the problem. For transient problems, the initial conditions are also defined. The simulation is started and the equations are solved iteratively as a steady-state or transient. Finally, a postprocessor is used for the analysis and visualization of the resulting solution.

The F-16 data is-

\begin{tabular}{|l|l|}
\hline Crew: & 1 \\
\hline Wing area: & $300 \mathrm{ft}^{2}\left(27.87 \mathrm{~m}^{2}\right)$ \\
\hline Airfoil: & NACA $64 \mathrm{~A} 204$ root and tip \\
\hline Length & $: 49 \mathrm{ft} .5$ in $(15.06 \mathrm{~m})$ \\
\hline Wingspan: & $32 \mathrm{ft} .8$ in $(9.96 \mathrm{~m})$ \\
\hline
\end{tabular}

\section{ANALYSIS IN ANSYS WORKBENCH USING ANSYS FLUENT}

\section{CFD Simulation}

The simulation of thecontinuum was done in ANSYS Fluent 16. In this initially, the meshing of the continuum was read and then checked. Once the software approves it, the scale was selected in mm as the model was created and meshed using the unit $\mathrm{mm}$. Then the models, materials and boundary conditions were set. 
- Turbulence Models: The turbulence models used for these simulations were the k- $\varepsilon$ model (Realizable) and k- $\omega$ SST. The solver was based on "density-based" as the all of the simulations were compressible. Energy equations were selected in order to solve the cases as all of the simulations were compressible.

- Materials: The working fluid in this simulation was an ideal gas as the boundary condition "Pressure Far-field" was compatible with it. It was considered the F-16 aircraft was flying at sea level conditions and the viscosity was solved using Sutherland equations.

- Boundary Conditions: Pressure far-field boundary conditions were used in this simulation to model a freestream compressible Flow at infinity, with free-stream Mach number and static conditions specified. The aircraft was given with "wall” boundary condition.

- Solution: The solver was a semi-implicit method for pressure-linked equations (SIMPLE) algorithm. This algorithm is an iterative procedure for solving equations for velocity and pressure, for steady-state. The Courant number is set to 2 and the under-relaxation factors for momentum and pressure are set as 0.8 and for the turbulent kinetic energy, turbulent dissipation rate and turbulent viscosity is set to 0.8. For the discretization, the pressure was kept as standard, while the other parameters Momentum, Turbulent Kinetic Energy, Turbulent dissipation Rate and Energy were retained as Second Order Upwind. Monitoring the convergence during the solution was dynamically checked by force coefficient values rather than checking for the convergence of residuals. The data were printed, reported and displayed in the plots of lift, drag, and moment coefficients, and residuals for the solution variables. On the Force Monitors, the Force vectors Lift and Drag had to define with relative to the free stream direction.

\section{ANSYS ADAPTATION}

\begin{tabular}{|c|c|}
\hline $\begin{array}{l}\text { SETUP } \\
\text { GENERAL } \square\end{array}$ & \\
\hline \multicolumn{2}{|l|}{ Scale Domain extents } \\
\hline $\mathrm{Xmin}(\mathrm{mm})$ & $=-15 \mathrm{Xmax}(\mathrm{mm})=60$ \\
\hline$Y \min (\mathrm{mm})$ & $15 \mathrm{Ymax}(\mathrm{mm})=15$ \\
\hline $\mathrm{Zmin}(\mathrm{mm})$ & $=-20 \mathrm{Zmax}(\mathrm{mm})=20$ \\
\hline \multicolumn{2}{|l|}{ Check $\Longleftrightarrow \mathrm{Ok}$} \\
\hline \multicolumn{2}{|l|}{ REPORT QUALITY } \\
\hline Minimum Orthogonal Quality & $=7.77495 \mathrm{e}-03$ \\
\hline Maximum Ortho Skew & $=9.66586 \mathrm{e}-01$ \\
\hline Maximum Aspect Ratio & $4.22296 \mathrm{e}+01$ \\
\hline $\begin{array}{c}\text { SOLVER } \\
\text { Type } \\
\end{array}$ & $=$ Density Based \\
\hline Velocity Formulation & Absolute \\
\hline Time & Steady/Dynamic \\
\hline $\begin{array}{l}\text { MODELS } \\
\text { Energy }\end{array}$ & On \\
\hline Viscous & Realizable K-e, Standard Wall Functions \\
\hline $\begin{array}{l}\text { MATERIALS } \\
\text { Fluid }\end{array}$ & Air \\
\hline Density $\left(\mathrm{Kg} / \mathrm{M}^{3}\right)$ [variable] & $1.225 @$ @sea-level \\
\hline Cp (Specific Heat) (j/Kg-K) [constant] & 1006.43 \\
\hline Thermal Conductivity (W/m-K) [constant] & 0.0242 \\
\hline Viscosity (Kg/m-s) [constant] & $1.7894 \mathrm{e}-05$ \\
\hline Solid & Aluminium \\
\hline Density $\left(\mathrm{Kg} / \mathrm{M}^{3}\right)$ & 2719 \\
\hline
\end{tabular}




\begin{tabular}{|c|c|}
\hline \multicolumn{2}{|c|}{ Table: Contd., } \\
\hline Cp (Specific Heat) (j/Kg-K) & 871 \\
\hline Thermal Conductivity $(\mathrm{W} / \mathrm{m}-\mathrm{K})$ & 202.4 \\
\hline
\end{tabular}

Table

\begin{tabular}{|l|c|}
\hline CELL ZONE CONDITIONS & Air \\
Zone & Fluid \\
\hline Type & 101325 pascal \\
\hline Operating Pressure & 1.2 \\
\hline $\begin{array}{l}\text { BOUNDARY CONDITIONS } \\
\text { Domain [Pressure Far field] - Mach Number }\end{array}$ & $\begin{array}{c}\text { Stationary } \\
\text { Wall }\end{array}$ \\
\hline F-16 [Wall] & 1.2 \\
\hline Inlet [Pressure Far Field / Velocity Inlet] - Mach Number & 386.37 \\
\hline X - Component Flow Direction & 103.527 \\
\hline Y - Component Flow Direction & 0 \\
\hline Z- Component Flow Direction & 1.2 \\
\hline Outlet [Pressure Far Field / Outflow] - Mach Number & 1 \\
\hline REFERENCE VALUES & 1.225 \\
\hline Area (m $\left.{ }^{2}\right)$ & 0 \\
\hline Density (kg/m3) & 1000 \\
\hline Enthalpy (j/kg) & 0 \\
\hline Length (mm) & 0 \\
\hline Pressure (Pascal) & 1 \\
\hline Temperature (k) & $1.7894 \mathrm{e}-05$ \\
\hline Velocity (m/s) & 1.4 \\
\hline Viscosity (kg/m-s) & \\
\hline Ratio of Specific Heats & \\
\hline
\end{tabular}

\begin{tabular}{|c|c|}
\hline $\begin{array}{l}\text { SOLUTION } \\
\text { Formulation }\end{array}$ & Implicit \\
\hline Flux Type & Roe-FDS \\
\hline \multicolumn{2}{|l|}{ Spatial Discretization } \\
\hline Gradient & least Squares Method \\
\hline Flow & Second Order Upwind \\
\hline Turbulent Kinetic Energy & Second Order Upwind \\
\hline Turbulent Dissipation Rate & Second Order Upwind \\
\hline \multicolumn{2}{|l|}{$\begin{array}{l}\text { Convergence Acceleration for } \\
\text { Stretched Mesh }\end{array}$} \\
\hline $\begin{array}{l}\text { SOLUTION CONTROLS } \\
\text { Courant Number }\end{array}$ & 2 \\
\hline \multicolumn{2}{|l|}{ Under Relaxation Factors } \\
\hline Turbulent Kinetic Energy & 0.8 \\
\hline Turbulent Dissipation Rate & 0.8 \\
\hline Turbulent Viscosity & 1 \\
\hline Solid & 1 \\
\hline \multicolumn{2}{|l|}{ Solution Limits } \\
\hline Minimum Absolute Pressure (Pascal) & 1 \\
\hline $\begin{array}{l}\text { Maximum Absolute Pressure } \\
\text { (Pascal) }\end{array}$ & $5 e+10$ \\
\hline Minimum Static Temperature (K) & 1 \\
\hline Maximum Static Temperature (K) & 5000 \\
\hline $\begin{array}{l}\text { Minimum Turbulent Kinetic Energy } \\
\left(\mathrm{M}^{2} / \mathrm{S}^{2}\right)\end{array}$ & $1 \mathrm{e}-14$ \\
\hline $\begin{array}{l}\text { Minimum Turbulent Dissipation } \\
\text { Rate }\left(\mathrm{M}^{2} / \mathrm{S}^{3}\right)\end{array}$ & $1 \mathrm{e}-20$ \\
\hline
\end{tabular}




\begin{tabular}{|l|c|}
\hline \multicolumn{2}{|c|}{ Table: Contd., } \\
\hline Maximum Turbulent Viscosity Ratio & 100000 \\
\hline Positivity Rate Limit & 0.2 \\
\hline $\begin{array}{l}\text { MONITORS } \\
\text { Residuals - Convergence Criteria }\end{array}$ & 0.04 \\
\hline $\mathrm{C}_{\mathrm{d}}, \mathrm{C}_{\mathrm{l}}, \mathrm{C}_{\mathrm{m}}$ & $\mathrm{F}-16$ \\
\hline $\begin{array}{l}\text { Static Pressure, Dynamic Pressure, } \\
\text { Turbulent Kinetic Energy, Turbulent } \\
\text { Dissipation Rate }\end{array}$ & $\mathrm{F}-16$ \\
\hline $\begin{array}{l}\text { SOLUTION INITIALIZATION } \\
\text { RUN CALCULATON }\end{array}$ & 10000 (Reference) \\
\hline Number of Iterations & 1 \\
\hline Reporting Interval & Ok - Run Calculation. \\
\hline Check Case & \\
\hline
\end{tabular}

\section{MESH}

In CFD Analysis, we change the incoming airflow, we get some cases. These cases are discussed below where the 3-important factor is calculated that is pressure, drag force and lift force. Due to these forces, we take so many cases for the drag and lift force are rising but a point will come where the drag and lift for values will decrease. So, let see the cases

The expected graphical results are set of residuals, lift coefficient, and drag coefficient. The contour results are inthe pressure and Mach number are evaluated.

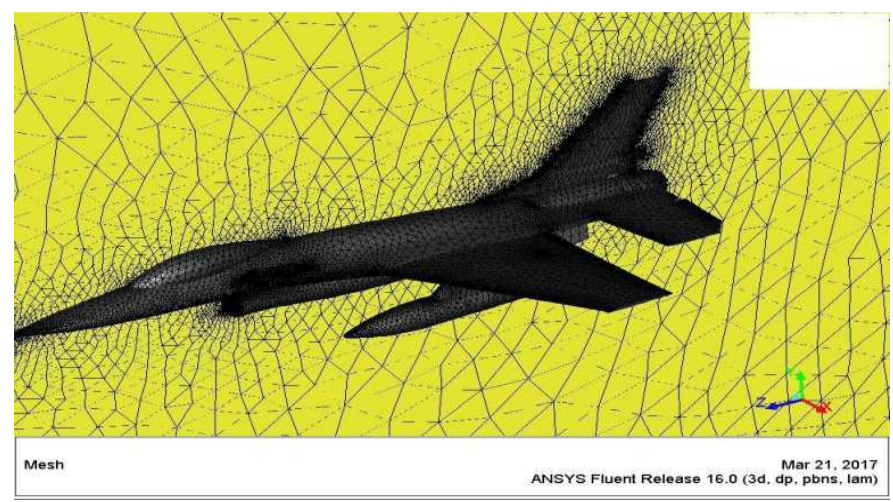

Figure 2: Mesh of the F-16

\section{RESULTS AND DISCUSSSIONS}

\section{PLOTS}
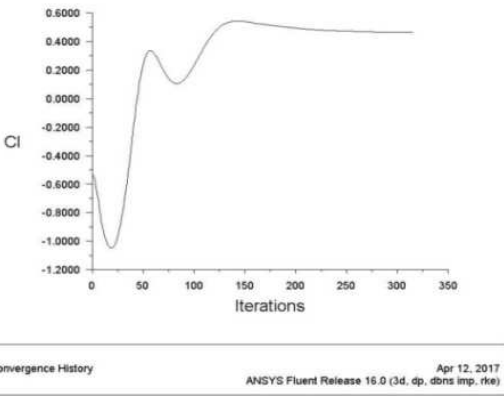

(a)

Figure 3 (a): Lift Coefficient Convergence History plot

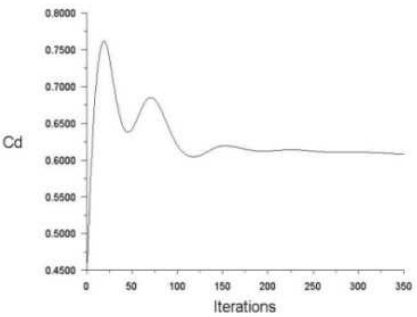

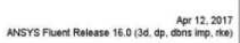

(b)

Figure 3(b): Drag coefficient Convergence History plot 
From figure 3(a), plots show that initially $C_{1}$ is negative, for the supersonic fighter due to the negative stability of aircraft to take off and pitch up to steady state. From figure 3 (b) plots show that initially $\mathrm{C}_{\mathrm{d}}$ is higher, because of the velocity decrement and there is a decrement in the drag.

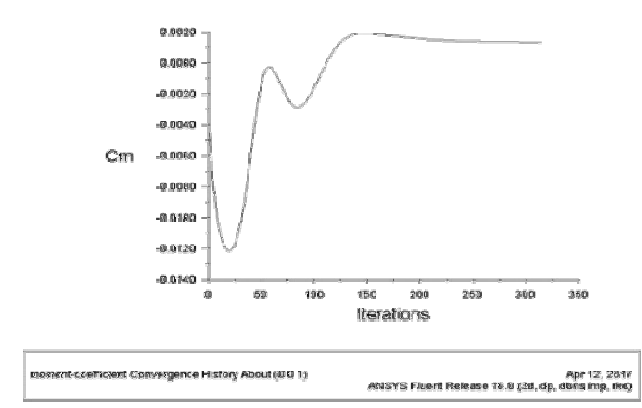

(c)

Figure 3 (c): Moment Coefficient Convergence History

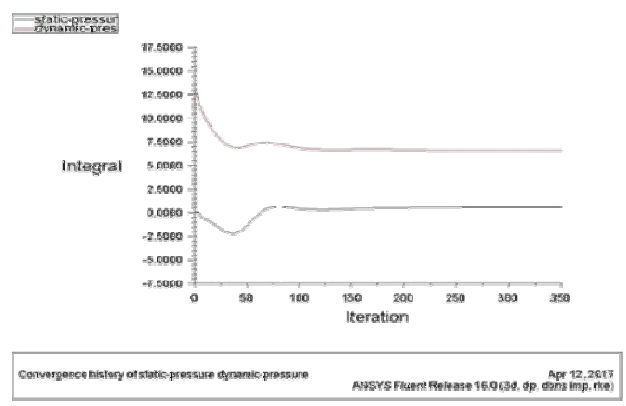

(d)

Figure 3 (d): Scaled Residuals

From figure 3 (c), 3(d) one can observe that the moment Coefficient is comparatively constant

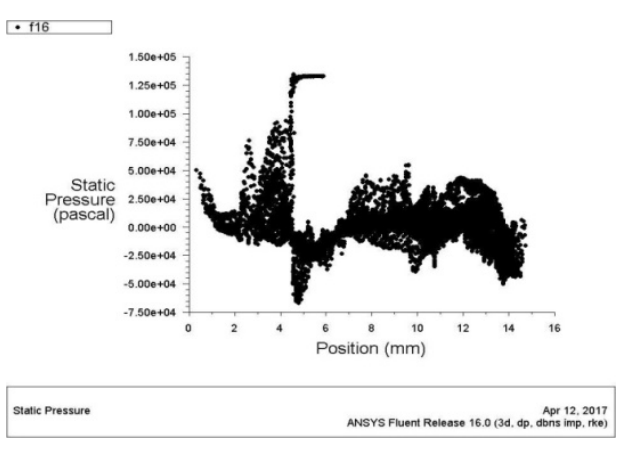

(a)

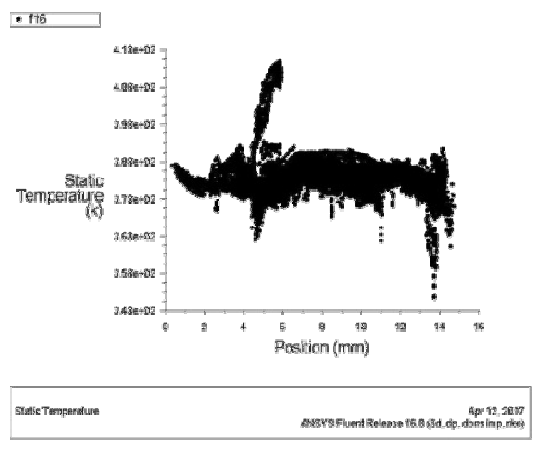

(b)

Figure 4(a): Static Pressure on F-16

Figure 4(b): Static Temperature on F-16

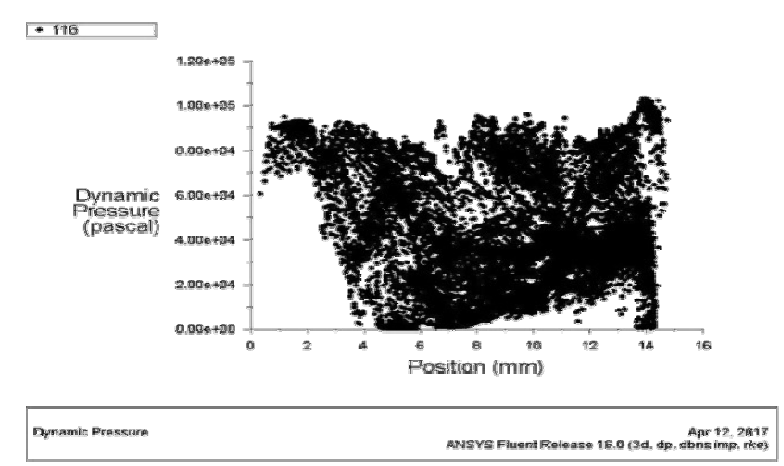

Figure 4(c): Dynamic Pressure on F-16

From figure 4(a) it can be seen that static pressure is initially decreasing and has reached to a higher level then reduced and finally maintaining the constant pressure. It's due to the surface flow interaction on the body of the F-16. From figure 4 (b) the static temperature variations can be seen. Initially, it's maintaining the constant speed then to reaching the higher level at the surface of the wing portion of aircraft because of its design, having edges and curved surfaces at the tip of the wing. From figure 4 (c) the dynamic pressure initially increasing and decreasing gradually and the distribution of dynamic pressure is varying continuously and reached to a higher level. 


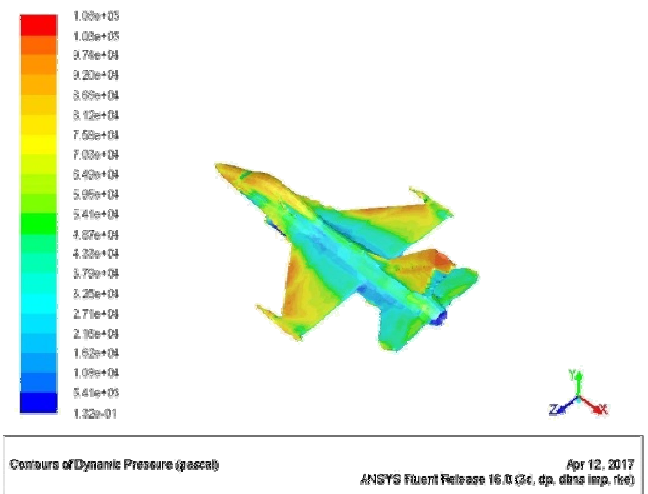

(a)

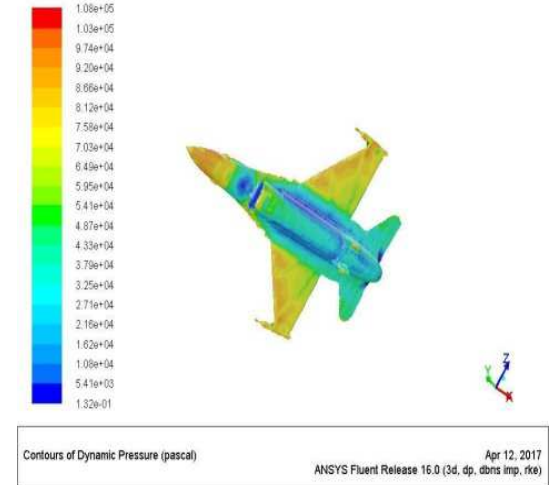

(b)

Figure 5 (a): Contours of Dynamic Pressure on F-16

Figure 5 (b): Contours of Dynamic Pressure on F-16

From figure 5 (a), 5 (b) we can see that dynamic pressure is varying higher at a certain portion and low at the certain portion of the aircraft. This is due to the design of F-16. At the sharp edges that are a leading edge of the F-16 aircraft and at the leading edge of the wing surface at some portions of the aircraft, we can observe dynamic pressure is more. The dynamic pressure is decreasing at the tail portion of the F-16 at Mach 1 at 0 degrees AoA.

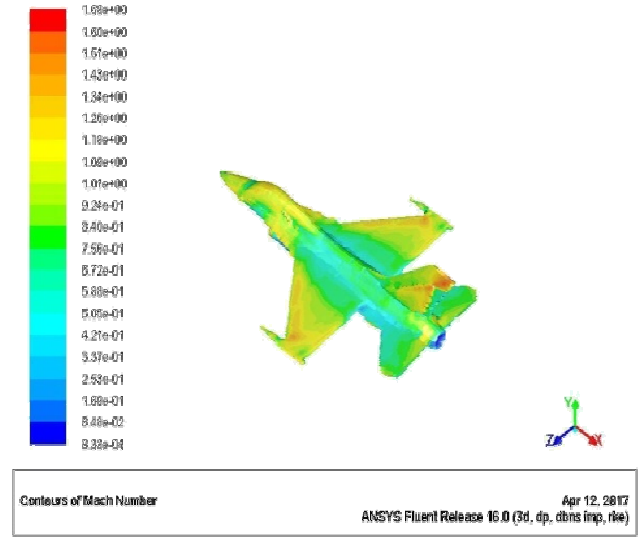

(c)

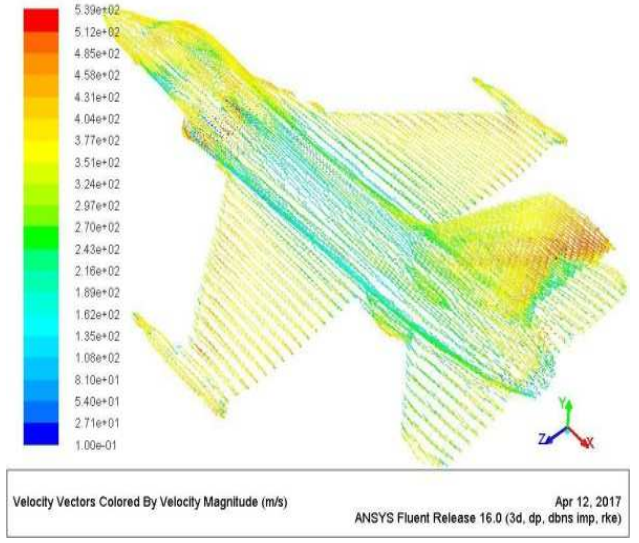

(d)

Figure 5 (c): Contours of Mach Number

Figure 5 (d): Velocity Vectors of Velocity Magnitude

From figure 5 (a), 5 (b) the variation of velocity seems to be higher at some portions and lower at some other portions on the surface of the F-16. It can be seen that the X-component velocity is higher at the curved and edge portions of the surface of F-16. As pressure is less at this portions velocity seems to be increased with increasing Mach and varying angles of attack of the aircraft by $0^{\circ}, 5^{\circ}, 10^{\circ}$, and 150 . 


\section{Velocity vs Angle of Attack}

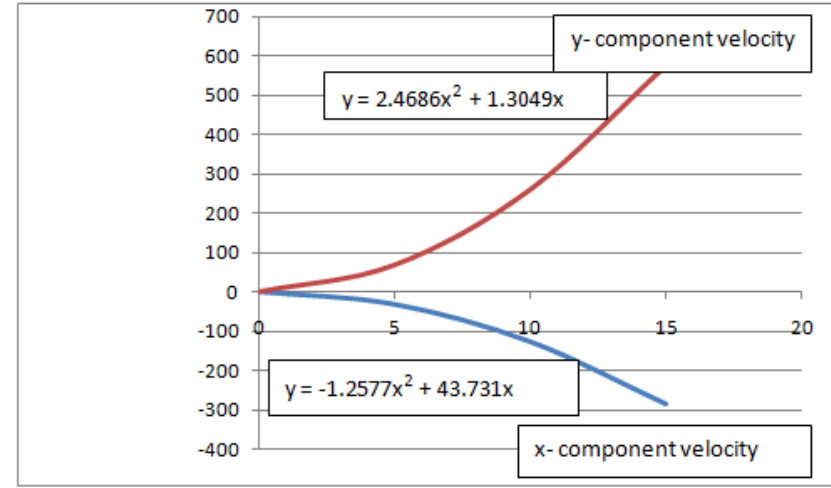

Figure 6: Flow Velocity Varying with Time and Angle of Attack

It can be seen that for a different angle of attacks that is $0,5,10,15$-degree angle of attack the variation in the velocity and pressure is studied on F-16 aircraft. The aerodynamic coefficients, $\mathrm{C}_{\mathrm{l}}, \mathrm{C}_{\mathrm{d}}, \mathrm{Cm}$ and studied and validated with the F-16 aircraft. Finally, results for velocity of X-Component and velocity of Y-Component versus different angle of attack at $0,5,10,15$ degree were calculated and obtained results seem too satisfy with referenced data that is $\mathrm{X}$ Component velocity is decreasing with Angle of attack and Y-component of velocity seems to be increasing with increase in Angle of attack.

\section{CONCLUSIONS}

CFD analysis of F-16 aircraft was conducted and studied and compared with referred values. Here the design of the F-16 aircraft and the meshing of F-16 with accuracy play a key role. The validated mesh is chosen and then an aerodynamic analysis is done. The design of F-16 and the valued mesh chosen here for the present work gives validated results. The static pressure, dynamic pressure and aerodynamic coefficients of F-16 aircraft results are obtained. The varying of pressure, temperature, and velocity on the surface of the aircraft are clearly studied and are compared with the referred values and seems to be the nearer value of approaches. The change in velocity with a different angle of attacks was studied and is compared.

\section{FUTURE SCOPE}

The future scope of this project lies in the fact that the aerodynamic analysis of an aircraft is a vast field of research and development. So, it can be seen that the R\&D can be done in the fields of aero-acoustics, fluid-structure interactions, etc. For this project, the flow is assumed to be incompressible and for a zero-degree angle of attack. So, the research can be done for compressible flow and various values of angle of attack.

\section{REFERENCES}

1. Malik, Murjeeb R., and Dennis M. Bushnell. "Role of Computational Fluid Dynamics and Wind Tunnels in Aeronautics R and D." (2012).

2. Gabbard, Mark D., Ned J. Lindsley, and Donald L. Kunz. "Modeling the Effects of under wing Missile Canards on F-16 Limit Cycle Oscillations." Journal of Aircraft (2015).

3. Sharma, Manish, T. Ratna Reddy, and Ch Indira Priyadarsini. "Flow analysis over an F-16 Aircraft using Computational Fluid Dynamics." International Journal of Emerging Technology and Advanced Engineering 3, no. 5 (2013). 
4. Boelens, Okko J., and James M. Luckring. "Flow Analysis of the F-16XL Aircraft (CAWAPI-2) at Transonic Flow Conditions." AIAA757 (2014): 13-17.

5. Boelens, O. J., K. J. Badcock, S. Gortz, S. Morton, W. Fritz, S. L. Karman Jr, T. Michal, and J. E. Lamar. "F-16XL geometry and computational grids used in Cranked-Arrow Wing Aerodynamics Project International." Journal of Aircraft 46, no. 2 (2009): 369.

6. B.J.M.Rao et al., CFD Analysis of Hydrodynamic Studies of a Bubbling Fluidized Bed, International Journal of Mechanical and Production Engineering Research and Development (IJMPERD), Volume 7, Issue 6, November - December 2017, pp. $341-350$

7. Boelens, O. J., K. J. Badcock, A. Elmilgui, Khaled S. Abdol-Hamid, and Steven J. Massey. "Comparison of measured and block structured simulation results for the F-16XL aircraft." Journal of Aircraft 46, no. 2 (2009): 377-384.

8. Davis, M. Bruce, Christopher Reed, and Patrick Yagle. "Hybrid grid solutions on the (CAWAPI) F-16XL using Falcon v4." AIAA paper 680 (2007): 8-11

9. Fritz, Willy, M. Bruce Davis, Steve L. Karman Jr, and Todd Michal. "Reynolds-Averaged Navier-Stokes solutions for the CAWAPI F-16XL using different hybrid grids." Journal of Aircraft 46, no. 2 (2009): 409.

10. Peiris, H. A. M., P. V. S. Nirmal, H. M. H. H. S. Bandara, D. M. Mahindarathne, and SLMD Rangajeeva and RMPS Bandara. "Aerodynamics Analysis of F-16 Aircraft."

11. Hitzel, Stephan M. "Vortex Flows of the F-16XL Configuration-CAWAPI-II Free-Flight Simulations." AIAA 758 (2014): 1317.

12. General dynamics of F-16 Falcon Aircraft Wikipedia 